\title{
A family pedigree of malignancies associated with BRCA1 pathogenic variants: a reflection of the state of art in China
}

\author{
Wenhui Li, Lei Li* ${ }^{*}$ and Ming Wu
}

\begin{abstract}
Background: Little is known about the status of genetic counseling for ovarian cancer in China.

Case presentation: We report a four-generation Chinese family with several types of cancer. The proband was a patient with high-grade serous ovarian cancer (HGSOC) who was found to harbor a pathogenic BRCA1 variant. Cosegregation analysis identified 7 of 9 relatives with the same deleterious variant. One month after the genetic test, one female carrier 54 years of age was diagnosed with stage IVB HGSOC, and another female 55 years of age accepted risk-reducing salpingo-oophorectomy, which revealed occult cancer of the fallopian tube (Stage IA).

Conclusions: Genetic counseling and testing for ovarian cancer in China have fallen behind international trends. Innovative studies and practices are urgently needed to establish models for cancer screening, prevention and treatment.
\end{abstract}

Keywords: BRCA mutations, Ovarian cancer, Genetic counseling, Risk-reducing salpingo-oophorectomy

\section{Background}

Ovarian cancer is the leading cause of cancer-related mortality among females without an effective screening strategy [1]. Inherited breast cancer susceptibility gene $1 / 2(B R C A 1 / 2)$ mutations, the most commonly mutated genes in high-grade serous ovarian carcinoma (HGSOC), account for the majority of cases of familial ovarian cancer [2]. As many as 13 to $20 \%$ of patients diagnosed with epithelial ovarian cancer (EOC) carry a BRCA1/2 mutation [3], and the lifelong cumulative risk of EOC is reportedly 44 and $17 \%$ for BRCA1 and BRCA2 mutation carriers, respectively [3]. Genetic counseling and testing are recommended for women with a history of ovarian cancer, and further cosegregation analysis is essential for the blood relatives of patients with positive test results. Those who harbor BRCA1/2 deleterious mutations should be offered intensive screening and prevention strategies, and risk-reducing salpingo-oophorectomy (RRSO) should be recommended at an appropriate age for $B R C A$ mutation carriers $[4,5]$. However, in China,

\footnotetext{
*Correspondence: lileigh@163.com

Department of Obstetrics and Gynecology, Peking Union Medical College

Hospital, Chinese Academy of Medical Sciences, Shuaifuyuan No 1,

Dongcheng District, Beijing 100730, China
}

there are few official genetic counseling clinics and/or models for EOC.

We report a pathogenic $B R C A$ variant-related family pedigree of malignancies. We also searched PubMed, EMBASE and SCOPUS, databases of clinical trials (clinicaltrial.gov, and who.int/ictrp/network/en/), and the website of the Chinese Human Genetic Resources Management Office of the National Ministry of Science and Technology (http://www.most.gov.cn/bszn/new/rlyc/jgcx/ index.htm) for reports and/or studies on the topics of genetic counseling of gynecologic cancer in China. We include a discussion on the limitations, potential strategies, and policies regarding genetic counseling for the Chinese population.

\section{Case presentation}

This study was approved by the Institutional Review Board of Peking Union Medical College Hospital. All involved family members provided informed consent in anticipation of the study. Data for all family members, including sex, tumor type, and age at death, were collected in detail (Fig. 1, according to the recommendations of the National Society of Genetic Counselors [6]). The proband (III-7) was a 59-year-old female diagnosed

(c) The Author(s). 2019 Open Access This article is distributed under the terms of the Creative Commons Attribution 4.0 International License (http://creativecommons.org/licenses/by/4.0/), which permits unrestricted use, distribution, and 


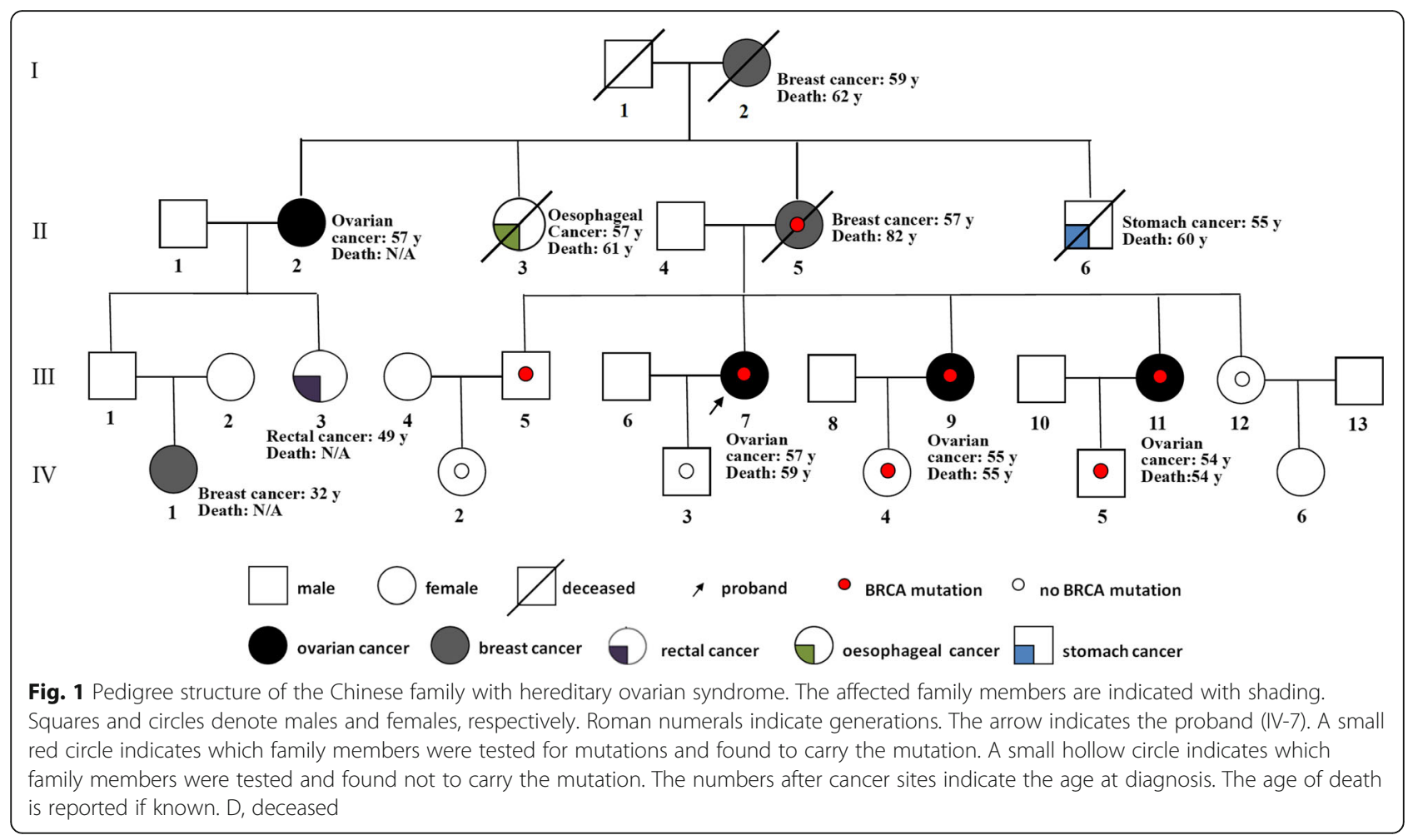

with HGSOC at the age of 57 years. Her grandmother (I-2) and mother (II-5) both died of breast cancer. The proband's mother had two sisters, one of whom died of esophageal cancer at the age of approximately 60 years (II-3). The other sister had ovarian cancer of unknown type (II-2), and she had a daughter diagnosed with rectal cancer, an unaffected son and a granddaughter with breast cancer. The proband's uncle (II-6) died of stomach cancer in his 60s. Before January 2018, four siblings of the proband did not show any evidence of malignancy.

In January 2018, the proband and her family members were referred to the genetic counseling clinics for gynecologic oncology at Peking Union Medical College Hospital. Germline sequencing using a 25-gene panel, i.e., BRCA1, BRCA2, CHEK2, PALB2, BRIP1, EPCAM, TP53, PTEN, STK11, CDH1, ATM, BARD1, MLH1, MRE11A, MSH2, MSH6, MUTYH, NBN, NF1, PMS1, PMS2, RAD50, RAD51C, RAD51D and SMARCA4, by BGI Clinical Diagnostic Laboratory (Shenzhen, China) was provided for the proband. Target-region capture and second-generation high-throughput sequencing were employed to analyze the exons and adjacent \pm 10 -bp intron variations of relevant genes. The test revealed a heterozygous pathogenic deletion mutation in BRCA1 exon 8, NG_005905.2 (NM_007294.3):g.25529_31240del, which was validated by quantitative polymerase chain reaction (qPCR) instead of the Sanger method. The qPCR results by $\mathrm{BGI}$ was used to validate the copy number variant
(CNV) detected in our study. Specific primers were designed to evaluate exon CNVs. DNA samples were diluted to $25 \mathrm{ng} / \mu \mathrm{l}$ and added to a house mixture; qPCR was performed using an ABI StepOne real-time PCR system (BGI Clinical Diagnostic Laboratory, Shenzhen, China). The detailed testing information is provided in Additional file 1: Table S1. The variants were classified into 5 categories according to American College of Medical Genetics (ACMG) recommendations [7].

Thereafter, from February to March 2018, qPCR cosegregation analysis of the BRCA1 mutation was conducted for nine family members (II-5, III-5, - 9, - 11, 12, IV-2, $-3,-4,-5)$. The results are presented in Fig. 1. Despite thorough clarification and education about the potential negative influence of testing on juveniles, one 14-year-old girl accepted cosegregation analysis at her parents' request and consent after the permission from the Institutional Review Board of the study center. Counseling about cancer prevention and targeted therapy was provided to all adult mutation carriers. Due to their age, a suggestion of RRSO was provided to both sisters of the proband (III-9 and III-11; 54 and 55 years, respectively). In April 2018, just 1 month after the genetic test, one of the proband's sister (III-11) developed massive ascites and metastasis to the supraclavicular lymph nodes. Pathology of the biopsied material confirmed stage IVB HGSOC. She accepted neoadjuvant chemotherapy and interval debulking surgery. In May 
2018, the other sister of the proband (III-9) accepted RRSO with hysterectomy. Pathological examination in accordance with the Sectioning and Extensively Examining the Fimbriated End Protocol (SEE-FIM) [8] revealed an infiltrating lesion of $0.5 \mathrm{~mm}$ in the right fallopian tube (Fig. 2), which coincided with the diagnosis of fallopian tube carcinoma at International Federation of Gynecology and Obstetrics (FIGO) stage IA. After sufficient discussion, she refused further staging surgery or prophylactic chemotherapy and decided to follow meticulous supervision mainly consisting of CA125 and transvaginal ultrasound. She remained well after the diagnosis at 7 months of follow-up. The chronology of the genetic tests and RRSO for the entire family is listed in Table 1.

\section{Discussion}

The case presented herein is a classical hereditary malignancy caused by $B R C A$ pathogenic variants. Nevertheless, in China, both genetic counseling/testing and prophylactic intervention have fallen behind the process required based on international guidelines, which is a reflection of the current status. Chinese oncologists and patients are both seriously uninformed regarding tests for inherited ovarian cancers because of poor education and counseling $[9,10]$, despite several national cohort studies about $B R C A$ germline mutations [11-13]. In our search of genetic counseling for gynecologic cancer in China, no specific studies were retrieved, except for two reports from Hong Kong [14, 15] and two ongoing trials (NCT03015376 and NCT03291106, clinicaltrials.gov). To our knowledge, there is only one genetic counseling clinic on gynecologic malignancy operating in

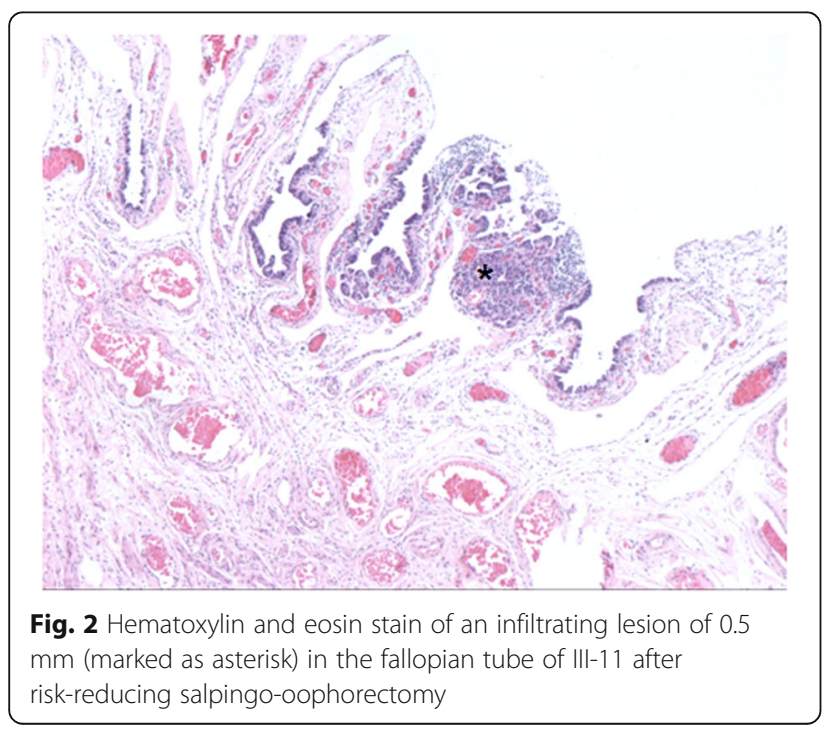

Table 1 Chronicle of the genetic tests and risk-reducing salpingo-oophorectomy (RRSO) for the reported family

\begin{tabular}{|c|c|}
\hline Date & Events \\
\hline January, 2018 & $\begin{array}{l}\text { The proband (III-7) received a } 25 \text {-gene panel } \\
\text { targeted genetic test and was confirmed as } \\
\text { deleterious } B R C A 1 \text { carrier. }\end{array}$ \\
\hline $\begin{array}{l}\text { February to } \\
\text { March, } 2018\end{array}$ & $\begin{array}{l}\text { Pedigree validation was performed for nine } \\
\text { family members (II-5, III-5, 9, 11, 12, IV-2, 3, 4, 5), } \\
\text { and seven (II-5, III-5, 9, 11, 12, IV-4, 5) were } \\
\text { confirmed as deleterious mutation carriers. }\end{array}$ \\
\hline April, 2018 & $\begin{array}{l}\text { One family member (III-11) was diagnosed with } \\
\text { high-grade serous ovarian carcinoma of stage IV. } \\
\text { She accepted neoadjuvant chemotherapy and } \\
\text { interval debulking surgery. }\end{array}$ \\
\hline May, 2018 & $\begin{array}{l}\text { One family member (III-9) accepted RRSO and } \\
\text { hysterectomy, and was diagnosed with primary } \\
\text { carcinoma of the fallopian tube of Stage IA (lesion } \\
\text { size of } 0.5 \mathrm{~mm} \text { ). She asked for observation and } \\
\text { refused further therapy. }\end{array}$ \\
\hline
\end{tabular}

mainland China [9], and no counselors have received formal training, assessment or certification. Thus far, the Chinese medical care system has not covered the expenses of mutation screening for high-risk individuals and/or families, even though cost concerns may contribute to low testing rates of population-based samples for at-risk cancer survivors [16]. All of these deficiencies have limited the development and promotion of genetic counseling for hereditary ovarian cancer and Lynch syndrome-associated endometrial cancer.

Timely and precise counseling, testing and cosegregation analysis should be offered to all women recently diagnosed with epithelial ovarian cancer as well as to their relatives [17], which is generally welcome but is contextualized within the broader experiences of these women [18]. Nonetheless, genetic testing was provided to most of the females of older ages in our report. The lack of testing and intervention resulted in the unfortunate event of rapidly evolved EOD in the proband's sister (III-11). However, genetic testing was provided for a 14-year-old juvenile at her parents' insistence, a step that is against the current general recommendation [4], as malignancies associated with BRCA1/2 mutations generally have an adult onset. Decisions about whether to offer genetic testing and screening should be driven by the best interest of the child [19]. Despite extensive counseling about the possible negative effect of testing, the girl's parents insisted on the test. However, there are no existing rules, regulations, or laws regarding appropriate genetic testing in China. In general, the potential impairment and injury of genetic testing on juveniles need further exploration. Rational counseling and informed consent should follow evidenced-based guidelines and the specific cultural environment and should be 
driven by the best interest of the child [19]. Regardless, genetic testing for asymptomatic children in this report is beyond the authors' consensus and general practice, and the flaw and limitation in current professional and administrative regulations should be addressed in a timely manner.

An approximate fourfold increase in precancerous lesions or occult cancer was reported to result from the use of the SEE-FIM protocol as opposed to the classical method [20]. Within the context of the traditional culture and physician-patient relationship, prophylactic interventions have been more difficult to perform than general testing, and it was reported that Chinese $B R C A$ mutation carriers have higher rates of surveillance than prophylactic surgery or the use of chemoprevention drugs [9]. To date, there is only one registered clinical trial regarding RRSO with the SEEFIM protocol in China (NCT03294343, clinicaltrials. gov). The siblings of the proband in our study were at relatively older ages when they received genetic testing and RRSO, likely leading to the occurrence of advanced HGSOC (III-11, 54 years old) and stage IA fallopian tube carcinoma (III-9, 55 years old).

A national policy is critical for counseling, testing and prophylactic surgery for populations at high risk of cancer [21], especially in China, a developing country with a vast population. Improvements in healthcare infrastructure will be required to realize population-level benefits from $B R C A$ genetic counseling and testing [22]. Furthermore, resources available within national and local agencies, professional societies, and in advocacy and community groups are critical for the successful implementation of cascade testing [23]. A public health approach for low-income women can be successful when integrated with the efforts of existing safety net organizations [24]. Possible approaches to overcome the disparity of genetic counseling include the use of patient navigators, online social media, or electronic medical records-based decision support aids [25]. In the future, the integration of genetic testing for $B R C A 1 / 2$ into the social health insurance for women with EOC should be developed as a policy of national public health care for Chinese patients.

\section{Conclusions}

Very few clinical trials and counseling clinics on hereditary ovarian cancer are available for the majority of patients and their families in China. Appropriate and timely cosegregation analysis and interventions for reducing ovarian cancer risks are urgently needed, as is a national policy supporting and regulating such research and practices.

\section{Supplementary information}

Supplementary information accompanies this paper https://doi.org/10. 1186/s13053-019-0126-4.

Additional file 1: Table S1. Details of the genetic testing for the proband. (DOCX 16 kb)

\section{Abbreviations}

HGSOC: High-grade serous ovarian carcinoma; QPCR: Quantitative polymerase chain reaction; RRSO: Risk-reducing salpingo-oophorectomy; SEE-

FIM: Sectioning and Extensively Examining the Fimbriated End Protocol

\section{Acknowledgements}

None.

\section{Authors' contributions}

All authors have read and approved the manuscript. LL and MW conducted the research, collected the data and reviewed the manuscript. WL finished the manuscript composition.

\section{Funding}

This study was supported by the Chinese Academy of Medical Sciences Initiative for Innovative Medicine (CAMS-2017-I2M-1-002). The funders provided payment for genetic testing. The funders had no role in the study design, data collection and analysis, decision to publish, or preparation of the manuscript.

\section{Availability of data and materials}

All data generated or analyzed during this study are included in this published article and its supplementary information files.

\section{Ethics approval and consent to participate}

This study was approved by the Institutional Review Board of Peking Union Medical College Hospital (Registration No. ZS-1245 and HS-1474 for genetic tests and risk-reducing surgeries, respectively). The Chinese Human Genetic Resources Management Office of the National Ministry of Science and Technology approved this study (registration No. [2017]1901, http://www.most. gov.cn/bszn/new/rlyc/jgcx/index.htm). All family members provided informed consent.

\section{Consent for publication}

Written consent to publish this information was obtained from the study participants.

\section{Competing interests}

The authors declare that they have no competing interests.

Received: 1 February 2019 Accepted: 4 September 2019

Published online: 10 September 2019

\section{References}

1. Bray F, Ferlay J, Soerjomataram I, Siegel RL, Torre LA, Jemal A. Global cancer statistics 2018: GLOBOCAN estimates of incidence and mortality worldwide for 36 cancers in 185 countries. CA Cancer J Clin. 2018;68(6):394-424.

2. Hilton JL, Geisler JP, Rathe JA, Hattermann-Zogg MA, DeYoung B, Buller RE. Inactivation of BRCA1 and BRCA2 in ovarian cancer. J Natl Cancer Inst. 2002; 94(18):1396-406.

3. Kuchenbaecker KB, Hopper JL, Barnes DR, Phillips KA, Mooij TM, Roos-Blom MJ, Jervis S, van Leeuwen FE, Milne RL, Andrieu N, et al. Risks of breast, ovarian, and contralateral breast Cancer for BRCA1 and BRCA2 mutation carriers. JAMA. 2017;317(23):2402-16.

4. NCCN Clinical Practice Guidelines in Oncology (NCCN Guidelines ${ }^{\oplus}$ ). Genetic/familial high-risk assessment: breast and ovarian. Version 2.2019 -2018. https://www.nccn.org/professionals/physician_gls/pdf/genetics_ screening.pdf.

5. SGO Clinical Practice Statement: Next generation cancer gene panels versus gene by gene testing. 2014. https://www.sgo.org/clinical-practice/ guidelines/next-generation-cancer-gene-panels-versus-gene-by-genetesting/. 
6. Bennett RL, French KS, Resta RG, Doyle DL. Standardized human pedigree nomenclature: update and assessment of the recommendations of the National Society of genetic counselors. J Genet Couns. 2008;17(5):424-33.

7. Richards S, Aziz N, Bale S, Bick D, Das S, Gastier-Foster J, Grody WW, Hegde $M$, Lyon E, Spector E, et al. Standards and guidelines for the interpretation of sequence variants: a joint consensus recommendation of the American College of Medical Genetics and Genomics and the Association for Molecular Pathology. Genet Med. 2015;17(5):405-24.

8. Lee Y, Medeiros F, Kindelberger D, Callahan MJ, Muto MG, Crum CP. Advances in the recognition of tubal intraepithelial carcinoma: applications to cancer screening and the pathogenesis of ovarian cancer. Adv Anat Pathol. 2006;13(1):1-7.

9. Li L, Qiu L, Wu M. A survey of willingness about genetic counseling and tests in patients of epithelial ovarian cancer. Zhonghua Yi Xue Za Zhi. 2017;97(43):3412-5.

10. Qiu L, Li L, Wu M. Questionnaire survey on the attitude to genetic counseling and testing for gynecologic oncology by Chinese healthcare providers. J Reprod Med. 2018;27(1):49-54.

11. Li A, Xie R, Zhi Q, Deng Y, Wu Y, Li W, Yang L, Jiao Z, Luo J, Zi Y, et al. BRCA germline mutations in an unselected nationwide cohort of Chinese patients with ovarian cancer and healthy controls. Gynecol Oncol. 2018;151(1):145-52.

12. Shi $T$, Wang $P$, Xie $C$, Yin $S$, Shi D, Wei $C$, Tang W, Jiang $R$, Cheng X, Wei $Q$, et al. BRCA1 and BRCA2 mutations in ovarian cancer patients from China: ethnic-related mutations in BRCA1 associated with an increased risk of ovarian cancer. Int J Cancer. 2017;140(9):2051-9.

13. Wu X, Wu L, Kong B, Liu J, Yin R, Wen H, Li N, Bu H, Feng Y, Li Q, et al. The first Nationwide multicenter prevalence study of germline BRCA1 and BRCA2 mutations in Chinese ovarian Cancer patients. Int I Gynecol Cancer. 2017;27(8):1650-7.

14. Kwong A, Wong $\mathrm{CH}$, Shea C, Suen DT, Choi CL. Choice of management of southern Chinese BRCA mutation carriers. World J Surg. 2010;34(7):1416-26.

15. Kwong A, Chen JW, Shin W. A new paradigm of genetic testing for hereditary breast/ovarian cancers. Hong Kong Med J. 2016:22(2):171-7.

16. Steffen LE, Du R, Gammon A, Mandelblatt JS, Kohlmann WK, Lee JH, Buys SS, Stroup AM, Campo RA, Flores KG, et al. Genetic testing in a populationbased sample of breast and ovarian Cancer survivors from the REACH randomized trial: cost barriers and moderators of counseling mode. Cancer Epidemiol Biomark Prev. 2017;26(12):1772-80.

17. Arts-de Jong M, de Bock GH, van Asperen CJ, Mourits MJ, de Hullu JA, Kets $\mathrm{CM}$. Germline BRCA1/2 mutation testing is indicated in every patient with epithelial ovarian cancer: a systematic review. Eur J Cancer. 2016;61:137-45

18. Shipman H, Flynn S, MacDonald-Smith CF, Brenton J, Crawford R, Tischkowitz $M$, Hulbert-Williams NJ. Universal BRCA1/BRCA2 testing for ovarian Cancer patients is welcomed, but with care: how women and staff contextualize experiences of expanded access. J Genet Couns. 2017;26(6):1280-91.

19. Social $G$, Committee on Bioethics. Ethical and policy issues in genetic testing and screening of children. Pediatrics. 2013;131(3):620-2.

20. Lamb JD, Garcia RL, Goff BA, Paley PJ, Swisher EM. Predictors of occult neoplasia in women undergoing risk-reducing salpingo-oophorectomy. Am J Obstet Gynecol. 2006;194(6):1702-9.

21. Singer CF, Tan YY, Rappaport C. Identification and management of familia breast cancer in Austria. Horm Mol Biol Clin Invest. 2017;32(2). https://doi. org/10.1515/hmbci-2017-0025.

22. Bellcross CA, Leadbetter S, Alford SH, Peipins LA. Prevalence and healthcare actions of women in a large health system with a family history meeting the 2005 USPSTF recommendation for BRCA genetic counseling referral. Cancer Epidemiol Biomark Prev. 2013;22(4):728-35.

23. Committee Opinion No ACOG. 727: Cascade testing: testing women for known hereditary genetic mutations associated with Cancer. Obstet Gynecol. 2018;131(1):e31-e4.

24. Pasick RJ, Joseph G, Stewart S, Kaplan C, Lee R, Luce J, Davis S, Marquez T, Nguyen T, Guerra C. Effective referral of low-income women at risk for hereditary breast and ovarian Cancer to genetic counseling: a randomized delayed intervention control trial. Am J Public Health. 2016;106(10):1842-8,

25. Randall TC, Armstrong K. Health care disparities in hereditary ovarian Cancer: are we reaching the underserved population? Curr Treat Options in Oncol. 2016;17(8):39

\section{Publisher's Note}

Springer Nature remains neutral with regard to jurisdictional claims in published maps and institutional affiliations.

Ready to submit your research? Choose BMC and benefit from:

- fast, convenient online submission

- thorough peer review by experienced researchers in your field

- rapid publication on acceptance

- support for research data, including large and complex data types

- gold Open Access which fosters wider collaboration and increased citations

- maximum visibility for your research: over $100 \mathrm{M}$ website views per year

At BMC, research is always in progress.

Learn more biomedcentral.com/submissions 